\title{
Depression and Mania Induce Pro-inflammatory Activation of Macrophages Following Application of Serum from Individuals with Bipolar Disorder
}

\author{
Pamela Ferrari ${ }^{1,2, *}$, Mariana Migliorini Parisi ${ }^{3,4, *}$, Rafael Colombo ${ }^{1,5}$, Matheus Becker ${ }^{4,6}$, Gabriel Fries ${ }^{1,4}$, \\ Bruna Maria Ascoli ${ }^{1,2}$, Luiza Paul Géa ${ }^{1,7}$, Márcia Kauer-Sant'anna, ${ }^{1,2}$, Flávio Kapczinski ${ }^{1,2}$, Fábio Klamt ${ }^{4,6}$, \\ Fátima T.C.R. Guma ${ }^{3,8}$, Adriane Ribeiro 'Rosa ${ }^{1,2,7}$, Florencia M. Barbé-Tuana ${ }^{3,4}$ \\ ${ }^{1}$ Laboratory of Molecular Psychiatry, Hospital de Clínicas de Porto Alegre, Porto Alegre; ${ }^{2}$ Postgraduate Program: Psychiatry and Behavioral \\ Science, ${ }^{3}$ Laboratory of Molecular Biology and Bioinformatics, ${ }^{4}$ Postgraduate Program: Biochemistry, ${ }^{6}$ Laboratory of Cellular Biochemistry, \\ Department of Biochemistry, ${ }^{7}$ Department of Pharmacology and Postgraduate Program: Pharmacology and Therapeutics, Universidade Federal \\ do Rio Grande do Sul (UFRGS), Porto Alegre; ${ }^{5}$ Laboratory of Pharmacology and Physiology, Universidade de Caxias do Sul, Petrópolis; \\ ${ }^{8}$ Laboratory of Biochemistry and Cellular Biology of Lipids, Department of Biochemistry, ICBS/UFRGS, Porto Alegre, Brazil
}

\begin{abstract}
Objective: Evidence has suggested that immune imbalance is involved with bipolar disorder (BD); however, its precise mechanism is poorly understood. This study investigated whether biochemical changes in the serum from BD patients could modulate the phenotype of cultured macrophages.

Methods: Eighteen subjects with BD and five healthy individuals were included in this study. The human monocyte cell line U-937 was activated with phorbol 12-myristate 13-acetate (PMA) and polarization was induced with RPMI-1640 media supplemented with 10\% serum from each patient for 24 hours. Gene expression of selected M1 and M2 markers was assessed by quantitative PCR.

Results: Macrophages exposed to serum of manic and depressive BD patients displayed an increase of interleukin-1 $\beta$ $(6.40 \pm 3.47$ and $9.04 \pm 5.84$ vs. $0.23 \pm 0.11 ; p<0.05)$ and tumor necrosis factor- $\alpha(2.23 \pm 0.91$ and $2.03 \pm 0.45$ vs. $0.62 \pm 0.24 ; p=0.002$ and $p=0.004$, respectively) compared to euthymic group (there was no difference between euthymic and controls). In parallel, U-937 macrophages treated with serum of patients in acute episode displayed a down-regulation of CXCL9 $(0.29 \pm 0.20$ vs. $1.86 \pm 1.61 ; p=0.006)$ and CXCL10 expression $(0.36 \pm 0.15$ and $0.86 \pm 0.24$ vs. 1.83 \pm 0.88 ; $p<0.000$ and $p=0.04)$ compared to the euthymia group.

Conclusion: Our results are consistent with previous studies showing that changes in peripheral blood markers could modulate M1/M2 polarization in BD. The evidence of macrophages as source of inflammatory cytokines might be helpful to unravel how the mononuclear phagocyte system is involved in the etiology of BD.
\end{abstract}

KEY WORDS: Bipolar disorder; Cytokines; Chemokines; Macrophages; Polarization; U-937.

\section{INTRODUCTION}

Emerging evidence has shown that bipolar disorder (BD) is accompanied by the activation of immune-inflammatory pathways as indicated by the increased levels of pro-inflammatory cytokines, positive acute-phase pro-

Received: December 19, 2016/Revised: April 21, 2017

Accepted: April 28, 2017

Address for correspondence: Adriane Ribeiro Rosa, Pharm $\mathrm{D}, \mathrm{PhD}$

Laboratory of Molecular Psychiatry, Hospital de Clínicas de

Porto Alegre, Ramiro Barcelos 2350, Brazil

Tel: +55-51-33598845, Fax: +55-51-33598846

E-mail: adrianerrosa@gmail.com

*These authors contributed equally to this work. teins, complement factors and increased levels of T-cellrelated activation markers. ${ }^{1-6)}$ Furthermore, immune disturbances have been associated with progression of the disorder evidenced by multiple episodes, longer duration of illness and medical comorbidities. ${ }^{7-10)}$

Macrophages are responsible for innate immune response activation in the periphery and microglia, are the resident macrophages of the central nervous system (CNS). ${ }^{11)}$ Classically, activated microglia (M1) can produce inflammatory mediators that induce breakdown of the blood brain barrier leading to massive infiltration of immune peripheral cells and neuronal damage. On the other hand, alternatively activated microglia (M2) can

(ㄷ) This is an Open-Access article distributed under the terms of the Creative Commons Attribution Non-Commercial License (http://creativecommons.org/licenses/by-nc/4.0) which permits unrestricted non-commercial use, distribution, and reproduction in any medium, provided the original work is properly cited. 
produce anti-inflammatory cytokines that inhibit M1 microglia-mediated neuroinflammation. ${ }^{11-13)}$ Therefore, it has been hypothesized that activated macrophages and their counterparts in the brain, the microglia, produce inflammatory mediators that contribute to psychiatric diseases such as $B D .^{14)}$ One of the complexities in unravelling the contribution of inflammatory mediators has been the exploration of peripheral vs. central inflammation and where the source of the inflammation lies.

Given that macrophages are central mediators of the innate immune response and initiate cell mediated immune responses, here we interrogate whether biochemical changes in the serum from BD patients could modulate the phenotype of macrophages.

\section{METHODS}

\section{Participants}

Patients were recruited, by convenience, from the Bipolar Disorders Program at Hospital de Clínicas de Porto Alegre (Brazil). All patients received pharmacological treatment by their psychiatrist in a naturalistic manner. Inclusion criteria were age $>18$ years and fulfillment of the Diagnostic and Statistical Manual of Mental Disorders 4th edition, text revision (DSM-IV-TR) criteria for BD type 1 (Structured Clinical Interview for DSM-IV; SCID-I). Patients were divided into three groups according to their scores on the 17-item Hamilton Depression Rating Scale (HAM-D) and the Young Mania Rating Scale (YMRS). Participants with a HAM-D score of 16 or greater were included in the depressive group. Subjects with an YMRS score above 12 were included in the manic group. Subjects with a HAM-D score of 16 or greater and an YMRS score of 20 or greater were considered to be affected by a mixed state and were not included. Subjects with HAM-D and YMRS scores below 7 were included in the euthymic group. Exclusion criteria included DSM-IVTR diagnoses other than BD, current abuse of illicit substances (alcohol and abuse drugs) and presence of metabolic disorders such as diabetes, chronic inflammatory diseases (e.g., inflammatory bowel disease or rheumatoid arthritis), cancer or other severe medical conditions.

The control group consisted of healthy participants selected from a pool of volunteers at the hospital. They had no current or previous history and no first-degree family history of major psychiatric disorders, including dementia or mental retardation, assessed by the non-patient version of the SCID-I.

This study was carried out in accordance with the latest version of the Declaration of Helsinki and reviewed by the Research Ethics Committee of Clinical Hospital of Porto Alegre. All participants provided written informed consent after the nature of the procedures had been fully explained.

\section{Assessments}

Socio-demographic and clinical data were collected in an extensive interview session. Manic and depressive symptoms were evaluated using the YMRS and the Hamilton Depression Rating Scale, 21-item version (HDRS-21), respectively. ${ }^{15,16)}$

\section{Blood Collection and U-937 Cultures}

Ten milliliters of peripheral blood were drawn from outpatients by venipuncture into heparinized tubes and immediately centrifuged at 3,000 $\times g$ for 10 minutes for serum separation. Serum was collected and stored at $-80^{\circ} \mathrm{C}$ until use. U-937 monocytic cell line was obtained from Rio de Janeiro Cell Bank (www.bcrj.org.br) and maintained in RPMI-1640 media (Invitrogen, Carlsbad, CA, USA) supplemented with $10 \%$ heat-inactivated fetal bovine serum (FBS; Invitrogen), $2 \mathrm{mM}$ L-glutamine (Invitrogen), $100 \mathrm{U} / \mathrm{ml}$ penicillin and $100 \mathrm{mg} / \mathrm{ml}$ streptomycin (Invitrogen) at $37^{\circ} \mathrm{C}$ in $5 \% \mathrm{CO}_{2}$ humidified air incubator. U-937 differentiation into macrophages was performed after stimulation with $10 \mathrm{nM}$ of phorbol 12-myristate 13-acetate (PMA; Sigma Aldrich, St. Louis, MO, USA) for 72 hours. After differentiation, media from macrophage-PMA treated cells was replaced and incubated for additional 24 hours with fresh RPMI supplemented with $10 \%$ of serum from each outpatient or healthy control. All participants had fasted and blood was collected on the same day of the interview.

\section{RNA Isolation and Quantitative Reverse Transcription PCR}

Total RNA was isolated from polarized U-937 using Trizol Reagent (Invitrogen) in accordance with the manufacturer instructions. Reverse transcription was performed with M-MLV Reverse Transcriptase (Sigma-Aldrich) and random nonamers (Sigma-Aldrich) primers with $1.2 \mu$ g of RNA. Two micromilliliters of diluted cDNA (1:20) was used as template for PCR reactions with Platinum ${ }^{\circledR}$ Taq 
Polymerase (Life Technologies, Carlsbad, CA, USA) in a final volume of $20 \mu \mathrm{l}$ with specific primers for CCL13, CXCL9, CXCL10, interleukin (IL)-1 $\beta$, IL-10, STAT1, transforming growth factor (TGF) $\beta$ and tumor necrosis factor (TNF) $-\alpha{ }^{17)}$ The thermal cycling profile for all genes was an initial denaturation step at $94^{\circ} \mathrm{C}$ for 10 minutes followed by 40 cycles of 15 seconds at $94^{\circ} \mathrm{C}, 15$ seconds at $60^{\circ} \mathrm{C}$ and 15 seconds at $72^{\circ} \mathrm{C}$ for data acquisition. Reaction specificity and absence of primer-dimer formation were evaluated using melting curve analysis at the end of each run. Finally, we confirmed the presence of a single amplicon of the specified size by agarose gel electrophoresis. All reactions were carried out in a StepOnePlus ${ }^{\circledR}$ real-time PCR system (Applied Biosystems, Foster City, CA, USA). Relative ratios were calculated using the comparative cycle threshold (CT) method $(\Delta \Delta C T$ method), ${ }^{18)}$ normalized by the housekeeping genes (STAT1 and IL-10) specified by the GeNorm software (https:// genorm.cmgg.be) and calibrated by the average of the $\Delta C T$ of the group.

\section{Statistics}

The statistical analysis was performed with the IBM SPSS Statistics (ver.19 for Windows; IBM Co., Armonk, NY, USA). The four groups (healthy controls, euthymic, manic and depressive) were compared regarding clinical and socio-demographic characteristics using one-way analysis of variance (ANOVA), Kruskall-Wallis test or chi-squared test, as appropriate. All analyses were twotailed, and significance was set at $p<0.05$.

\section{RESULTS}

As demonstrated in Table 1, there were no differences in age, gender and body mass index between groups. Regarding pharmacological treatment, $50 \%$ of them (9 patients) were drug free, $11 \%$ were on mood stabilizers (lithium and valproate), 22\% were on mood stabilizers add on antipsychotic and 5\% were on lithium or antipsychotic montherapy. Pro-inflammatory markers associated with the M1 phenotype; IL-1 $\beta$, TNF- $\alpha$, CXCL10 and CXCL9 showed different patterns of mRNA expression between the groups (Fig. 1A-1D). In particular, U-937 cells that had been treated with serum from manic and depressive patients displayed a similar and robust up-regulation of IL-1 $\beta$ when compared with those treated with serum from euthymic patients $(6.40 \pm 3.47$ and $9.04 \pm$ 5.84 vs. $0.23 \pm 0.11 ; p<0.002$ and $p<0.001$, respectively). An increased expression of TNF- $\alpha$ was also found in U-937 cells treated with serum from depressive and manic patients compared to euthymic patients $(2.23 \pm 0.91$ and $2.03 \pm 0.45$ vs. $0.62 \pm 0.24 ; p=0.002$ and $p=0.004$, respectively). IL- $1 \beta(0.23 \pm 0.11$ vs. $0.28 \pm 0.065$; $p=0.355)$ and TNF- $\alpha$ expressions $(0.59 \pm 0.11$ vs. $0.62 \pm 0.24 ; p>0.05)$ were similar between healthy controls and euthymic patients. Conversely, U-937 macrophages treated with serum of depressive patients displayed a down-regulation of CXCL9 expression compared to healthy controls and euthymic patients $(0.29 \pm 0.20$ vs. $1.73 \pm 1.17$ and $1.86 \pm 1.61 ; p<0.007$ and $p=0.006$, respectively). No difference was observed in CXCL9 in manic patients. Decreased CXCL10 expression was found in both depressed and manic patients compared to euthymic group $(0.36 \pm 0.15$ and $0.86 \pm 0.24$ vs. $1.83 \pm 0.88 ; p<0.000$ and $p=0.04$, respectively). Healthy controls and euthymic patients were again similar regarding CXCL9 expression $(1.73 \pm 1.17$ vs. $1.86 \pm 1.61$; $p=0.806)$ and $\mathrm{CXCL} 10(1.71 \pm 0.66$ vs. $1.83 \pm 0.88 ; p=$

Table 1. Clinical and demographic characteristics of the participants

\begin{tabular}{|c|c|c|c|c|c|}
\hline Characteristic & Control $(n=5)$ & Remission $(n=8)$ & Depression $(\mathrm{n}=5)$ & Mania $(n=5)$ & $p$ value \\
\hline Gender, male & $2(40.0)$ & $4(50.0)$ & $2(40.0)$ & $2(40.0)$ & $0.212^{*}$ \\
\hline Age $(y r)$ & $39.00 \pm 19.02$ & $49.88 \pm 6.53$ & $47.40 \pm 11.14$ & $39.00 \pm 12.98$ & $0.320^{\dagger}$ \\
\hline BMI $\left(\mathrm{kg} / \mathrm{m}^{2}\right)$ & $26.54 \pm 6.75$ & $30.81 \pm 5.93$ & $28.27 \pm 7.38$ & $24.85 \pm 1.93$ & $0.408^{\dagger}$ \\
\hline Age at onset $(\mathrm{yr})$ & -- & $34.50 \pm 7.72$ & $43.00 \pm 10.19$ & $37.00 \pm 13.58$ & $0.368^{\dagger}$ \\
\hline HDRS & $0.20 \pm 0.44$ & $3.75 \pm 2.05$ & $24.20 \pm 8.25$ & $4.20 \pm 3.11$ & $<0.001^{\dagger}$ \\
\hline YMRS & -- & $0.88 \pm 0.99$ & $0.80 \pm 1.09$ & $20.20 \pm 3.03$ & $<0.001^{\dagger}$ \\
\hline Depressive episodes & -- & $9.38 \pm 10.46$ & $5.40 \pm 5.55$ & $2.20 \pm 4.38$ & $<0.001^{\dagger}$ \\
\hline Manic episodes & -- & $7.25 \pm 6.06$ & $8.75 \pm 12.97$ & $4.20 \pm 3.49$ & 0.655 \\
\hline
\end{tabular}

Values are presented as number (\%) or mean \pm standard deviation.

BMI, body mass index; HDRS, Hamilton Depression Rating Scale; YMRS, Young Mania Rating Scale.

Bold indicates significant $p$ values; ${ }^{*}$ chi-square test, ${ }^{\dagger}$ ANOVA. 


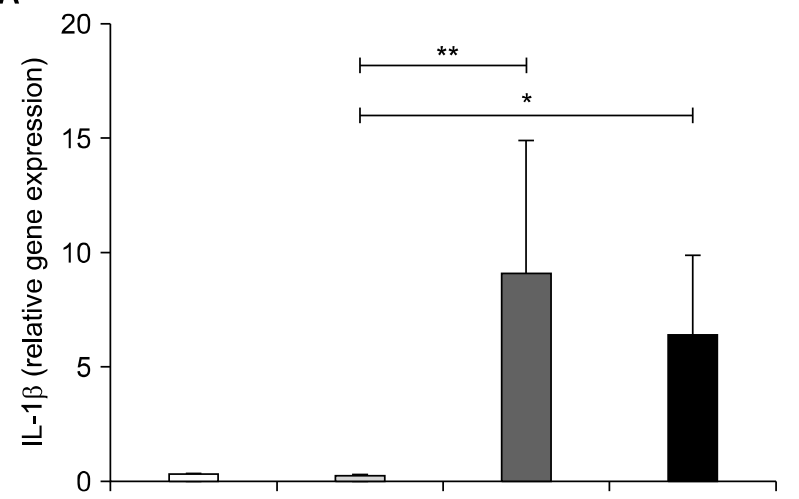

C

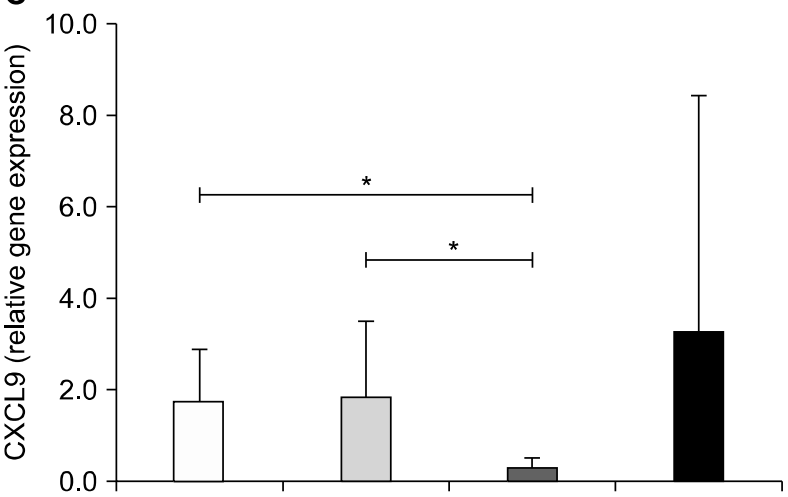

E

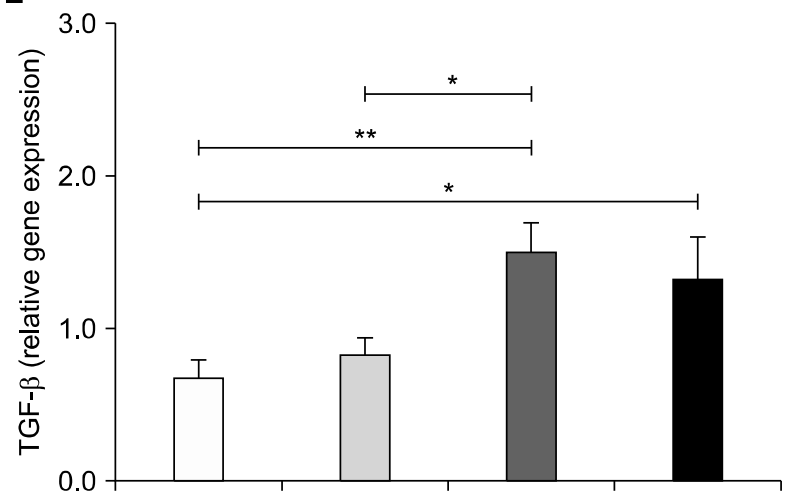

B

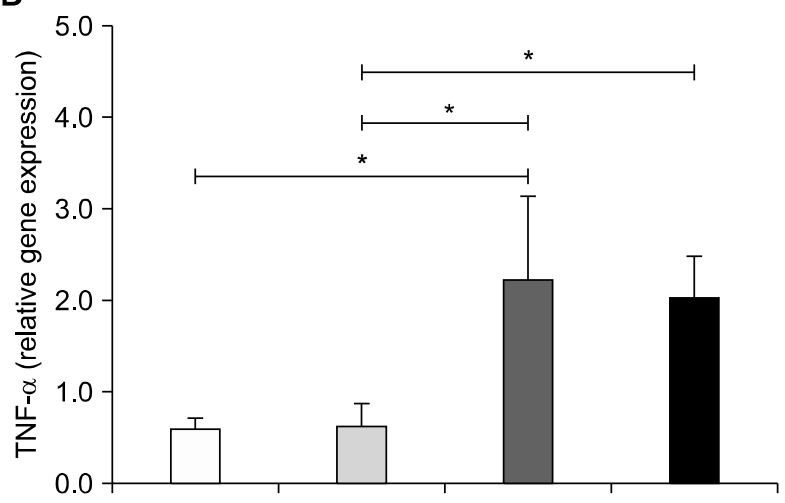

D

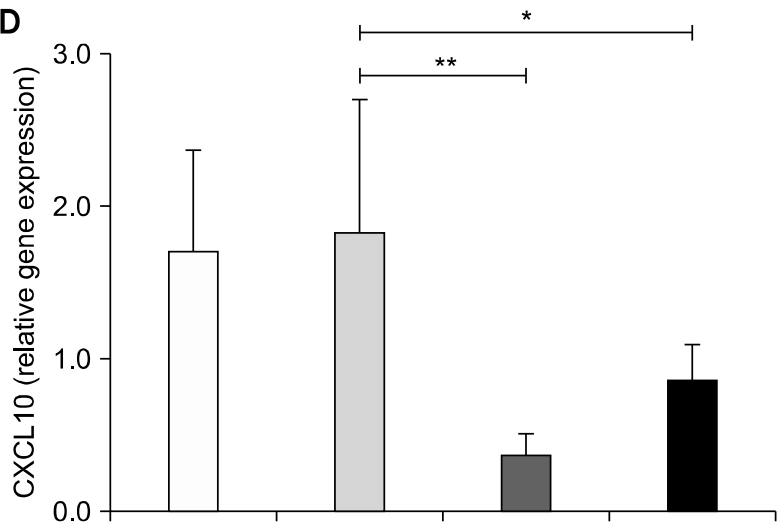

$\mathbf{F}$

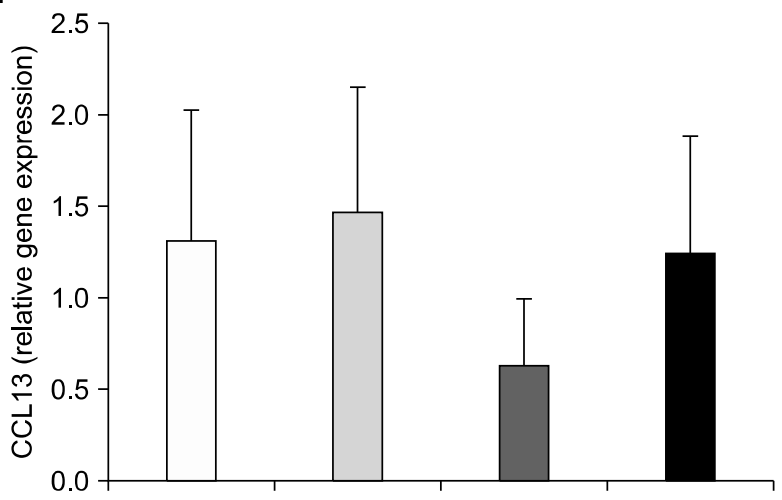

Fig. 1. Depression and mania induce pro-inflammatory activation of macrophages. Gene expression (per 0.5 cells/ml) of IL-1 $\beta$, TNF- $\alpha$, CXCL9 and CXCL10 inflammatory (M1) and TGF- $\beta$ and CCL13 regulatory (M2) cytokines and chemokines after in vitro polarization of U-937 macrophages with plasma obtained from bipolar patients $(n=18)$ and plasma from healthy individuals as a control group $(n=5)$. Data expressed as mean \pm standard deviation, Kruskall-Wallis test; ${ }^{*} p<0.05$ and ${ }^{* *} p<0.001$.

White bars, control group $(n=5)$; light grey bars, euthymia group $(n=8)$; dark grey bars, depression group $(n=5)$; black bars, mania group ( $n=5)$.

0.969).

Depressed BD patients displayed similar up-regulation of TGF- $\beta$ when compared with euthymic patients and both depressed and manic patients had higher TGF- $\beta$ levels than controls (there was no significant difference be- tween controls and euthymic patients; $0.81 \pm 0.12$ vs. $0.67 \pm 0.11 ; \quad p=0.275)$. No statistical significance $(p=0.061)$ was found for CCL13 expression among the groups (Fig. 1F). 


\section{DISCUSSION}

In the present study, we explored the hypothesis that biochemical changes in the serum of BD patients could modulate the phenotype of macrophages. Our results showed that macrophages exposed to from manic and depressed patients had an up-regulation expression of pro-inflammatory cytokines including IL- $1 \beta$ and TNF- $\alpha$, in parallel some chemokines (CXCL9 and CXCL10) secretion was down regulated compared to euthymic patients. Emerging evidence has shown that augmented macrophage-derived cytokines such as TNF- $\alpha$ and IL1- $\beta$ may be involved in the pathophysiology of BD. ${ }^{4,19-21)}$ Nonetheless, our findings suggest a critical role for macrophages as initiators or perpetuators of the systemic inflammation observed in BD patients, especially during acute episodes.

One of the hypothesis involved in the inflammatory theory of BD is related to the chronic activation and desensitization of the hypothalamic-pituitary-adrenal axis (HPA), and related to the susceptibility of patients to stress. ${ }^{22)}$ Chronic stress promotes a pronounced increase in cortisol content, which may attenuate the negative feedback exerted by this hormone on the HPA axis. The loss of the HPA axis homeostasis might promote a systemic increase of inflammatory cytokines with consequent spread of the inflammatory signal from the periphery to the CNS. ${ }^{23,24)}$ Persistent CNS inflammation induces activation of the microglia with secretion of larger amounts of TNF- $\alpha$ and IL-1 $\beta$, that may lead to neuronal apoptosis and decreased neurotransmitter synthesis. ${ }^{25,26)}$ Furthermore, microglia has been described as an important cellular type for the propagation of the inflammatory signal in the CNS, and some studies using positron emission tomography have shown an overactivation of microglia in the brain of individuals with various neuropsychiatric disorders, including BD. ${ }^{27)}$

There are limitations to this study. As the study was conducted based on a sample of convenience and within limited resources, the sample size is small. Additionally, patients were on pharmacological treatment and we can not rule out the effects of mood stabilizers and antipsychotics on present results. However, the study provides important information on the interactions of macrophages and inflammatory factors in BD. It highlights the need for additional studies addressing the ability of monocytes/macro- phages to polarize into $\mathrm{M} 1$ or $\mathrm{M} 2$ phenotypes in BD. Future studies should also consider exploring the effects of serum from BD patients on microglial cultures, to bridge the understanding of peripheral and central interactions, contributing to the etiology and pathophysiology of $\mathrm{BD}$.

\section{- Acknowledgments}

Mariana M. Parisi is recipient of scholarship from Conselho Nacional de Desenvolvimento Científico e Tecnológico (CNPq). Florencia M. Barbé-Tuana and Bruna M. Ascoli are scholarship recipients from Coordenação de Aperfeiçoamento de Pessoal de Nível Superior (CAPES). Adriane R. Rosa would like to thank the support of the CNPq. We would like to thank Olivia Dean for her input and English review in this work.

The authors of this paper do not have any commercial associations that might pose a conflict of interest in connection with this manuscript. Flávio Kapczinski has received grant/research support from Astra-Zeneca, Eli Lilly, Janssen-Cilag, Servier, CNPq, CAPES, NARSAD and Stanley Medical Research Institute; has been a member of the board of speakers for Astra-Zeneca, Eli Lilly, Janssen and Servier; and has served as a consultant for Servier.

This research received no specific grant from any funding agency in the public, commercial, or not-for-profit sectors.

\section{REFERENCES}

1. Bai YM, Su TP, Li CT, Tsai SJ, Chen MH, Tu PC, et al. Comparison of pro-inflammatory cytokines among patients with bipolar disorder and unipolar depression and normal controls. Bipolar Disord 2015;17:269-277.

2. Dargél AA, Godin O, Kapczinski F, Kupfer DJ, Leboyer M. C-reactive protein alterations in bipolar disorder: a meta-analysis. J Clin Psychiatry 2015;76:142-150.

3. do Prado CH, Rizzo LB, Wieck A, Lopes RP, Teixeira AL, Grassi-Oliveira R, et al. Reduced regulatory $T$ cells are associated with higher levels of Th1/TH17 cytokines and activated MAPK in type 1 bipolar disorder. Psychoneuroendocrinology 2013;38:667-676.

4. Fiedorowicz JG, Prossin AR, Johnson CP, Christensen GE, Magnotta VA, Wemmie JA. Peripheral inflammation during abnormal mood states in bipolar I disorder. J Affect Disord 2015;187:172-178.

5. Kauer-Sant'Anna M, Kapczinski F, Andreazza AC, Bond DJ, Lam RW, Young LT, et al. Brain-derived neurotrophic factor 
and inflammatory markers in patients with early-vs. late-stage bipolar disorder. Int I Neuropsychopharmacol 2009; 12:447458.

6. Knijff EM, Breunis MN, Kupka RW, de Wit HJ, Ruwhof C, Akkerhuis GW, et al. An imbalance in the production of IL-1beta and IL-6 by monocytes of bipolar patients: restoration by lithium treatment. Bipolar Disord 2007;9:743-753.

7. Ascoli BM, Géa LP, Colombo R, Barbé-Tuana FM, Kapczinski $\mathrm{F}$, Rosa AR. The role of macrophage polarization on bipolar disorder: Identifying new therapeutic targets. Aust N ZJ Psychiatry 2016;50:618-630.

8. Kapczinski F, Vieta E, Andreazza AC, Frey BN, Gomes FA, Tramontina J, et al. Allostatic load in bipolar disorder: implications for pathophysiology and treatment. Neurosci Biobehav Rev 2008;32:675-692.

9. Stertz L, Fries GR, Rosa AR, Kauer-Sant'anna M, Ferrari P, Paz $\mathrm{AV}$, et al. Damage-associated molecular patterns and immune activation in bipolar disorder. Acta Psychiatr Scand 2015; 132 : 211-217.

10. Vieta E, Popovic D, Rosa AR, Solé B, Grande I, Frey BN, et al. The clinical implications of cognitive impairment and allostatic load in bipolar disorder. Eur Psychiatry 2013;28:21-29.

11. Nakagawa Y, Chiba K. Diversity and plasticity of microg/ial cells in psychiatric and neurological disorders. Pharmacol Ther 2015;154:21-35.

12. Beumer W, Gibney SM, Drexhage RC, Pont-Lezica L, Doorduin J, Klein HC, et al. The immune theory of psychiatric diseases: a key role for activated microglia and circulating monocytes. J Leukoc Biol 2012;92:959-975.

13. Réus GZ, Fries GR, Stertz L, Badawy M, Passos IC, Barichello $\mathrm{T}$, et al. The role of inflammation and microg/ial activation in the pathophysiology of psychiatric disorders. Neuroscience 2015;300:141-154.

14. Smith RS. A comprehensive macrophage-T-lymphocyte theory of schizophrenia. Med Hypotheses 1992;39:248-257.

15. Williams JB. A structured interview guide for the Hamilton Depression Rating Scale. Arch Gen Psychiatry 1988;45: 742-747.

16. Young RC, Biggs JT, Ziegler VE, Meyer DA. A rating scale for mania: reliability, validity and sensitivity. Br J Psychiatry 1978;
133:429-435.

17. Becker M, De Bastiani MA, Parisi MM, Guma FT, Markoski MM, Castro MA, et al. Integrated transcriptomics establish macrophage polarization signatures and have potential applications for clinical health and disease. Sci Rep 2015;5:13351.

18. Livak KJ, Schmittgen TD. Analysis of relative gene expression data using real-time quantitative PCR and the 2(-Delta Delta $C(T))$ method. Methods 2001;25:402-408.

19. Munkholm K, Vinberg M, Berk M, Kessing LV. State-related alterations of gene expression in bipolar disorder: a systematic review. Bipolar Disord 2012;14:684-696.

20. Munkholm K, Braüner JV, Kessing LV, Vinberg M. Cytokines in bipolar disorder vs. healthy control subjects: a systematic review and meta-analysis. J Psychiatr Res 2013;47:11191133.

21. O'Brien SM, Scully P, Scott LV, Dinan TG. Cytokine profiles in bipolar affective disorder: focus on acutely ill patients. J Affect Disord 2006;90:263-267.

22. Fries GR, Vasconcelos-Moreno MP, Gubert C, dos Santos BT, Sartori J, Eisele B, et al. Hypothalamic-pituitary-adrenal axis dysfunction and illness progression in bipolar disorder. Int $\mathrm{J}$ Neuropsychopharmacol 2015;18:pyu043.

23. Qi XR, Kamphuis W, Wang S, Wang Q, Lucassen PJ, Zhou JN, et al. Aberrant stress hormone receptor balance in the human prefrontal cortex and hypothalamic paraventricular nucleus of depressed patients. Psychoneuroendocrinology 2013;38: 863-870.

24. Sinclair D, Fillman SG, Webster MJ, Weickert CS. Dysregulation of glucocorticoid receptor co-factors FKBP5, BAG1 and PTGES3 in prefrontal cortex in psychotic illness. Sci Rep 2013;3:3539.

25. Dantzer R, Kalin N. Salivary biomarkers of stress: cortisol and alpha-amylase. Psychoneuroendocrinology 2009;34:1.

26. Han QQ, Yu J. Inflammation: a mechanism of depression? Neurosci Bull 2014;30:515-523.

27. Haarman BC, Riemersma-Van der Lek RF, de Groot JC, Ruhé $\mathrm{HG}$, Klein HC, Zandstra TE, et al. Neuroinflammation in bipolar disorder - A [(11)C]-(R)-PK11195 positron emission tomography study. Brain Behav Immun 2014;40:219-225. 